\title{
Rapid oscillation of insulin release by the rat pancreatic islets under stringent $\mathrm{Ca}^{2+}$-free conditions
}

\author{
T Aizawa, T Kaneko, H Yajima, S Yamada, Y Sato, Y Kanda, \\ S Kanda, M Noda ${ }^{1}$, T Kadowaki ${ }^{1}$, M Nagai, K Yamauchi, \\ M Komatsu and $\mathbf{K}$ Hashizume
}

Department of Geriatrics, Endocrinology and Metabolism, Shinshu University School of Medicine, Matsumoto, Japan

${ }^{1}$ Department of Metabolic Diseases, Faculty of Medicine, University of Tokyo, Tokyo, Japan

(Requests for offprints should be addressed to T Aizawa; Email: traizawa@hsp.md.shinshu-u.ac.jp)

\begin{abstract}
Oscillation of insulin release by the pancreatic islets was evaluated under stringent $\mathrm{Ca}^{2+}$-free conditions for the first time. Isolated single rat islets were exposed to $16 \cdot 7 \mathrm{mM}$ glucose in the presence of $1.9 \mathrm{mM} \mathrm{Ca}^{2+}$, or under the stringent $\mathrm{Ca}^{2+}$-free conditions $\left(\mathrm{Ca}^{2+}\right.$ omission with $1 \mathrm{mM}$ EGTA, $6 \mu \mathrm{M}$ forskolin and $100 \mathrm{nM}$ phorbol 12-myristate 13 -acetate). Fifteen minutes after the initiation of glucose stimulation, effluent was collected at a 6-s interval, insulin was determined in duplicate by a highly sensitive insulin
\end{abstract}

radioimmunoassay, and oscillation and pulsatility of release statistically analyzed. Significant oscillation of insulin release was observed in all islets irrespective of presence and absence of $\mathrm{Ca}^{2+}$. Significant pulsatility of release was detected in 7 of 11 islets in the presence of $\mathrm{Ca}^{2+}$ and three of six islets in the absence of $\mathrm{Ca}^{2+}$. In conclusion, high glucose elicits oscillatory insulin release both in the presence and absence of extracellular $\mathrm{Ca}^{2+}$.

Journal of Endocrinology (2000) 166, 545-551

\section{Introduction}

Insulin release by individual isolated pancreatic islets was first investigated by Beigelman et al. (Beigelman et al. 1973a,b, 1976). Since then, data on insulin release by the single islets have been accumulated (Beigelman et al. 1973a,b, 1976, Rosario et al. 1986, Bergsten \& Hellman 1993a,b, Gilon et al. 1993, Bergsten et al. 1994, Gilon \& Henquin 1995, Bergsten 1995, Zaitsev et al. 1995, Westerlund et al. 1996, 1997), and it is now well established that pancreatic islets are the smallest units of coordinated insulin secretion. Even in the initial studies, it was noticed that a high concentration of glucose elicits pulsatile insulin release by single islets (Beigelman et al. 1973b, 1976). Especially in the presence of high concentration of $\mathrm{Ca}^{2+}$, temporal coupling between oscillations of cytosolic free $\mathrm{Ca}^{2+}$ concentration $\left(\left[\mathrm{Ca}^{2+}\right] \mathrm{i}\right)$ and insulin release is so tight (Gilon et al. 1993, Gilon \& Henquin 1995) that it looks apparent that the former is driving the latter. However, glucose stimulation of insulin release is not solely mediated by elevation of $\left[\mathrm{Ca}^{2+}\right] \mathrm{i}$ (Aizawa et al. 1992, 1994, Gembal et al. 1992, Sato et al. 1992, Komatsu et al. 1997, Aizawa et al. 1998, Henquin et al. 1998). In particular, glucose potently augments insulin release even under stringent $\mathrm{Ca}^{2+}$-free conditions (Komatsu et al. 1995, 1996, 1997, Aizawa et al. 1998, Sato et al. 1998, Yajima et al. 1999). In this communication, we report that glucose-stimulated insulin release occurs in a fine oscillatory manner in the order of seconds under the $\mathrm{Ca}^{2+}$-free conditions as well. The data implies that glucose produces non- $\mathrm{Ca}^{2+}$ signal or signals which promote coordination of islet $\beta$ cells leading to oscillation of insulin release.

\section{Materials and Methods}

Pancreatic islets were obtained from male, adult Wistar rats by collagenase dispersion and directly hand-picked (Sato et al. 1992, Aizawa et al. 1994, 1996, Taguchi et al. 1995, Asanuma et al. 1997) and used for the experiments within $2 \mathrm{~h}$. Exposure of the islets to Ficoll was intentionally avoided as previously recommended (Beigelman et al. 1973a). In this study, islets with the diameter of 200 $300 \mu \mathrm{m}$ were used. For isolation and subsequent washing of the islets, Krebs-Ringer bicarbonate (KRB) buffer containing (in $\mathrm{mM}$ ) $\mathrm{NaCl} 118 \cdot 4, \mathrm{KCl} 4 \cdot 7, \mathrm{MgSO}_{4} 1 \cdot 2$, $\mathrm{KH}_{2} \mathrm{PO}_{4} 1 \cdot 2, \mathrm{CaCl}_{2} 1 \cdot 9, \mathrm{NaHCO}_{3} 25$ (equilibrated with $5 \% \mathrm{CO}_{2}-95 \% \mathrm{O}_{2}, \mathrm{pH} 7 \cdot 4$ ), glucose $5 \cdot 5$, and $0 \cdot 1 \% \mathrm{BSA}$ was used, and the experiments were carried out at $37^{\circ} \mathrm{C}$ using the KRB buffer containing 0.2\% BSA as described (Sato et al. 1992, Aizawa et al. 1994, 1996, Taguchi et al. 1995, Asanuma et al. 1997) with minor modifications. The modifications were mostly down-sizing of the perifusion system: the volume of chamber and flow rate were 


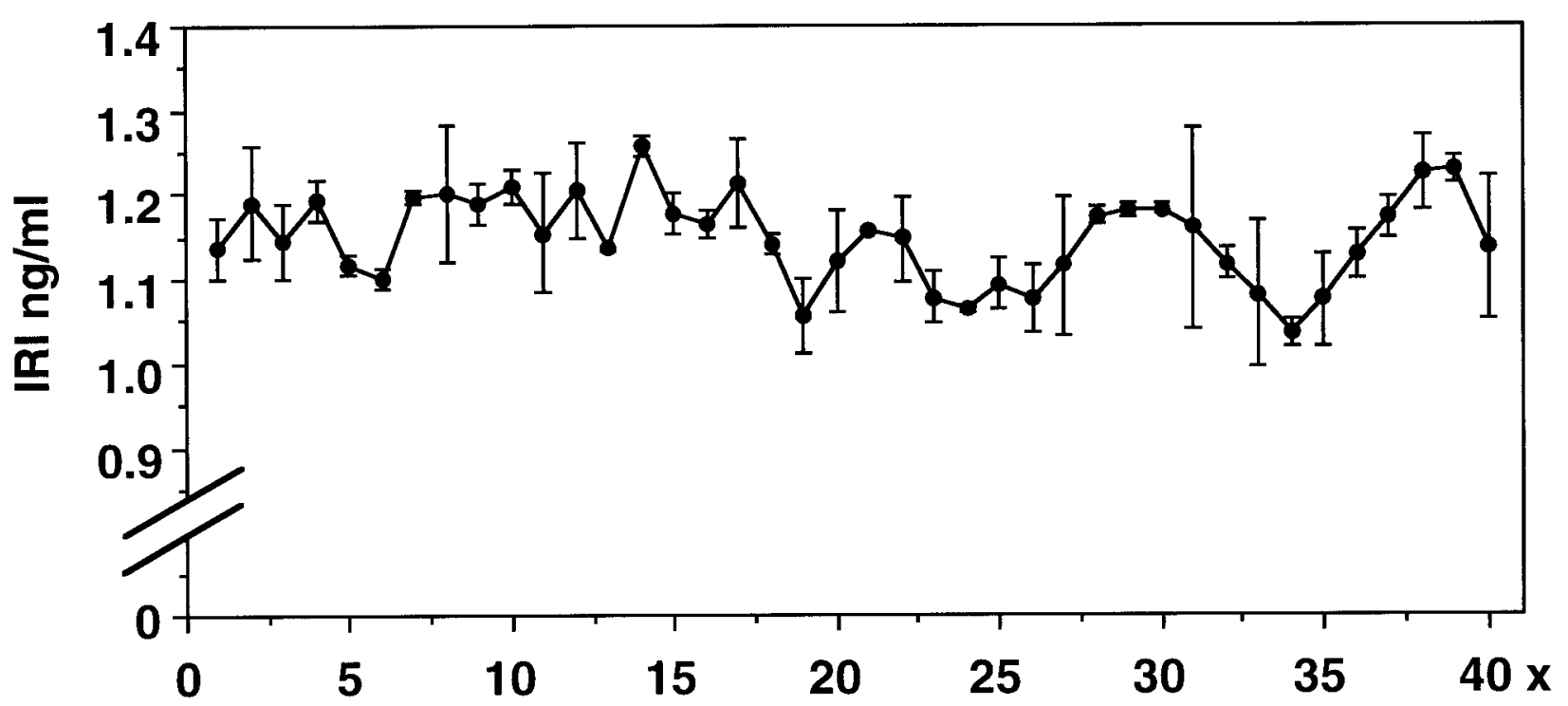

Figure 1 Assay variation in insulin radioimmunoassay. IRI stands for immunoreactive insulin. KRB buffer containing a known concentration of insulin was repetitively assayed in duplicate for 40 times. The evaluation was done on non-perifused sample, and the values were plotted to simulate variation of IRI in the real experiments. The values are means \pm ranges of the duplicate assay. See the Materials and Methods section for details. The conversion factor for ng to nmol is $0 \cdot 0001739$.

reduced to $20 \mu \mathrm{l}$ and $180 \mu \mathrm{l} / \mathrm{min}$ respectively. Two $5 \mathrm{ml}$ syringes were mounted on two identical syringe pumps (Pump 22, Harvard, South Natick, MA, USA), and one was used for pre-wash period and the other used for glucose stimulation period (see below). The accuracy of the flow was $\pm 1 \%$. Sephadex G-10 was used as supporting matrix and the plastic mesh, not a glass bead, was placed at the bottom of the chamber to prevent outflow of Sephadex. Pressure of the perifusion circuit was monitored in each experiment, and it was $<15 \mathrm{~cm} \mathrm{H}_{2} \mathrm{O}$ in all. Before starting glucose stimulation, the islets were perifused with $\mathrm{KRB}$ buffer containing $3 \mathrm{mM}$ glucose for $30 \mathrm{~min}$. In some experiments, $\mathrm{Ca}^{2+}$-omitted $\mathrm{KRB}$ buffer with $1 \mathrm{mM}$ EGTA $\left(\mathrm{Ca}^{2+}\right.$-free KRB buffer) was used as described (Komatsu et al. 1995). In brief, the islets were first incubated in the $\mathrm{Ca}^{2+}$-free $\mathrm{KRB}$ buffer containing $3 \mathrm{mM}$ glucose for $60 \mathrm{~min}$ at $37^{\circ} \mathrm{C}$. In this case, before exposure to high glucose, the islets were perifused with the $\mathrm{Ca}^{2+}$ free KRB buffer containing $3 \mathrm{mM}$ glucose, $6 \mu \mathrm{M}$ forskolin and $100 \mathrm{nM}$ phorbol 12-myristate 13-acetate (TPA) for $30 \mathrm{~min}$. Then, the $\mathrm{Ca}^{2+}$-free buffer was switched to the one with $16.7 \mathrm{mM}$ glucose with the continuous presence of forskolin and TPA.

Perifusate was collected as $7 \mu \mathrm{l}$ drops. Before the determination of oscillation, effluent was collected at 1-2 min intervals (see below). From $15 \mathrm{~min}$ after the initiation of glucose stimulation, effluent was collected at a 6 -s interval, i.e. mostly two drops per tube, and the oscillation of insulin release was determined. To minimize binding of insulin to the tube wall, silicon-coated glass tubes were used for collection of the effluent, the tubes were centri- fuged at $4{ }^{\circ} \mathrm{C}$ immediately after the collection and placed on ice, and insulin assay was performed on the same day. Insulin RIA was performed in duplicate (with a sampling volume of $6.5 \mu \mathrm{l}$ each) using high sensitivity rat insulin RIA kits (Linco Research Inc., St Louis, MO, USA): the minimum detectable amount of insulin was $1.0 \mathrm{pg} /$ tube, the half-maximum displacement occurred at approximately $10 \mathrm{pg} /$ tube, and the intra-assay coefficient of variation ((standard deviation/mean) $\times 100, \mathrm{CV}$ ) was $6.1 \%$ in single assay and $4.6 \%$ in duplicate assay, each performed by ourselves. To avoid inter-assay variation, all samples from one experiment were assayed together in one assay. Forskolin and TPA were obtained from Sigma (St Louis, MO, USA).

Statistical analysis was performed using WaldWolfowitz runs test, Mann-Whitney U-test, and $\chi^{2}$ test (StatView, SAS Institute Inc., Cary, NC, USA), and the partial autocorrelation plot (SYSTAT, SPSS, Chicago, IL, USA). $P<0 \cdot 05$ was considered significant. Data are presented as means \pm S.E.s unless otherwise indicated.

\section{Results}

Evaluation of non-specific variation in the insulin RIA

To critically evaluate the degree of assay variation in the RIA, KRB buffer with $0 \cdot 2 \%$ BSA containing a known concentration of insulin standard was consecutively assayed in duplicate with a $6.5 \mu \mathrm{l}$ sampling volume for 40 times. The values are plotted (Fig. 1) to simulate the experimental oscillation shown in other figures (Figs 3A and 4A 

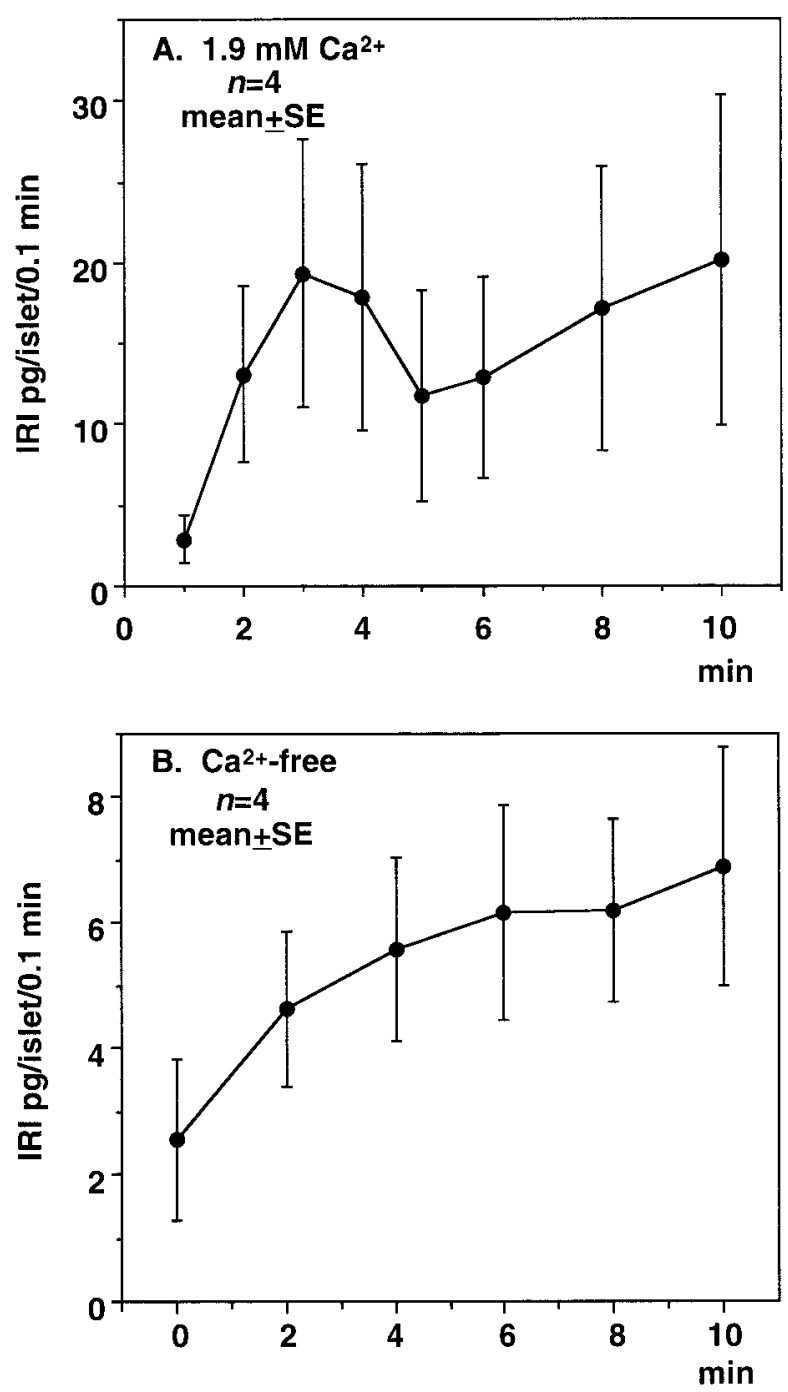

Figure 2 Insulin released by the single islets during the initial period of exposure to $16.7 \mathrm{mM}$ glucose in the presence of $1.9 \mathrm{mM} \mathrm{Ca}^{2+}(\mathrm{A})$ or under the stringent $\mathrm{Ca}^{2+}$-free conditions $\left(\mathrm{Ca}^{2+}\right.$ omission with $1 \mathrm{mM}$ EGTA, $6 \mu \mathrm{M}$ forskolin and $100 \mathrm{nM}$ TPA) (B). The data shown in this figure were obtained by the single assay with a sampling volume of $50 \mu \mathrm{l}$. The conversion factor for $\mathrm{pg} /$ islet to $\mathrm{nmol} /$ islet is $0 \cdot 1739$. IRI, immunoreactive insulin.

below). The variation obtained in this experiment was compared with that obtained in the real perifusion experiments by Wald-Wolfowitz runs test to know the significance of oscillation in each experiment (see below).

\section{Insulin release in the presence of regular $\mathrm{Ca}^{2+}$}

Insulin release was clearly increased in 10 out of 11 islets upon exposure to $16.7 \mathrm{mM}$ glucose (Fig. 2A). From $15 \mathrm{~min}$ after the initiation of glucose stimulation, perifusate was collected at a 6 -s interval for 3-5 min (Fig. 3A).
Statistically significant oscillation of insulin release, compared with the non-specific assay variation (Fig. 1), was detected in all islets responded to glucose. The CV value determined as an index of the degree of oscillation was $19 \cdot 3 \pm 1 \cdot 4 \%(n=10)$. In seven of them, significant pulsatility was detected by the partial autocorrelation plot (Fig. $3 \mathrm{~B})$. There were positive deflections with the intervals being $6 \mathrm{~s}$ (in five islets), and 18 and $30 \mathrm{~s}$ (in one islet each), and negative deflections with the intervals being $48 \mathrm{~s}$ (one islet), 36 and $54 \mathrm{~s}$ (one islet), and $54 \mathrm{~s}$ (one islet). In some islets, pulsatility with two different frequencies was detected as in Fig. 3B, II and IV.

Insulin release under the stringent $\mathrm{Ca}^{2+}$-free conditions

All six islets responded to $16.7 \mathrm{mM}$ glucose with gradual increase in the rate of insulin release under stringent $\mathrm{Ca}^{2+}$-free conditions $\left(\mathrm{Ca}^{2+}\right.$ omission with $1 \mathrm{mM}$ EGTA, $6 \mu \mathrm{M}$ forskolin and $100 \mathrm{nM}$ TPA) as previously reported (Komatsu et al. 1995, 1996, Sato et al. 1998, Yajima et al. 1999) (Fig. 2B). Fifteen minutes after the initiation of glucose stimulation, perifusate was collected at a 6-s interval for 3-5 $\mathrm{min}$ and oscillation of insulin release was determined (Fig. 4A). Statistically significant oscillation of insulin release, compared with the non-specific assay variation (Fig. 1), was detected in all six islets. The CV value obtained as an index of degree of oscillation was $13 \cdot 3 \pm 3 \cdot 4 \%(n=6)$. Using the partial autocorrelation plot, a significant pulse was detected in three islets (Fig. 4B, I-III). There was a 6-s interval positive deflection (Fig. 4B, I), a 30-s interval negative deflection (Fig. 4B, II), and 18- and 84-s interval negative deflections (Fig. 4B, III).

The CV value in the experiments under the stringent $\mathrm{Ca}^{2+}$-free conditions was smaller than that in the experiments with $1.9 \mathrm{mM} \mathrm{Ca}^{2+}(13 \cdot 3 \pm 3 \cdot 4$ vs $19 \cdot 3 \pm 1 \cdot 4 \%)$. However, the difference did not reach the statistically significant level $(P=0 \cdot 059)$.

\section{Discussion}

The insulinotropic action of glucose can be divided into at least three categories including (1) $\mathrm{K}^{+}$ATP channeldependent; (2) $\mathrm{K}^{+}$ATP channel-independent and $\mathrm{Ca}^{2+}$ dependent; and (3) $\mathrm{K}^{+}$ATP channel-independent and $\mathrm{Ca}^{2+}$ independent (Komatsu et al. 1997, Aizawa et al. 1998). The physiological role of $\mathrm{K}^{+} \mathrm{ATP}$ channel-independent glucose actions cannot be dismissed for in vivo regulation of insulin secretion where not only glucose but also incretins, amino acids, fatty acids, and neurotransmitters all act together to elicit insulin secretion (Aizawa et al. 1998, Yajima et al. 1999, Komatsu et al. 1999). In the present study, we tried to detect rapid oscillation and pulsatility of insulin release upon glucose stimulation, both in the presence of regular concentration of extracellular $\mathrm{Ca}^{2+}$ and under stringent $\mathrm{Ca}^{2+}$-free conditions. In the former condition, glucose is 

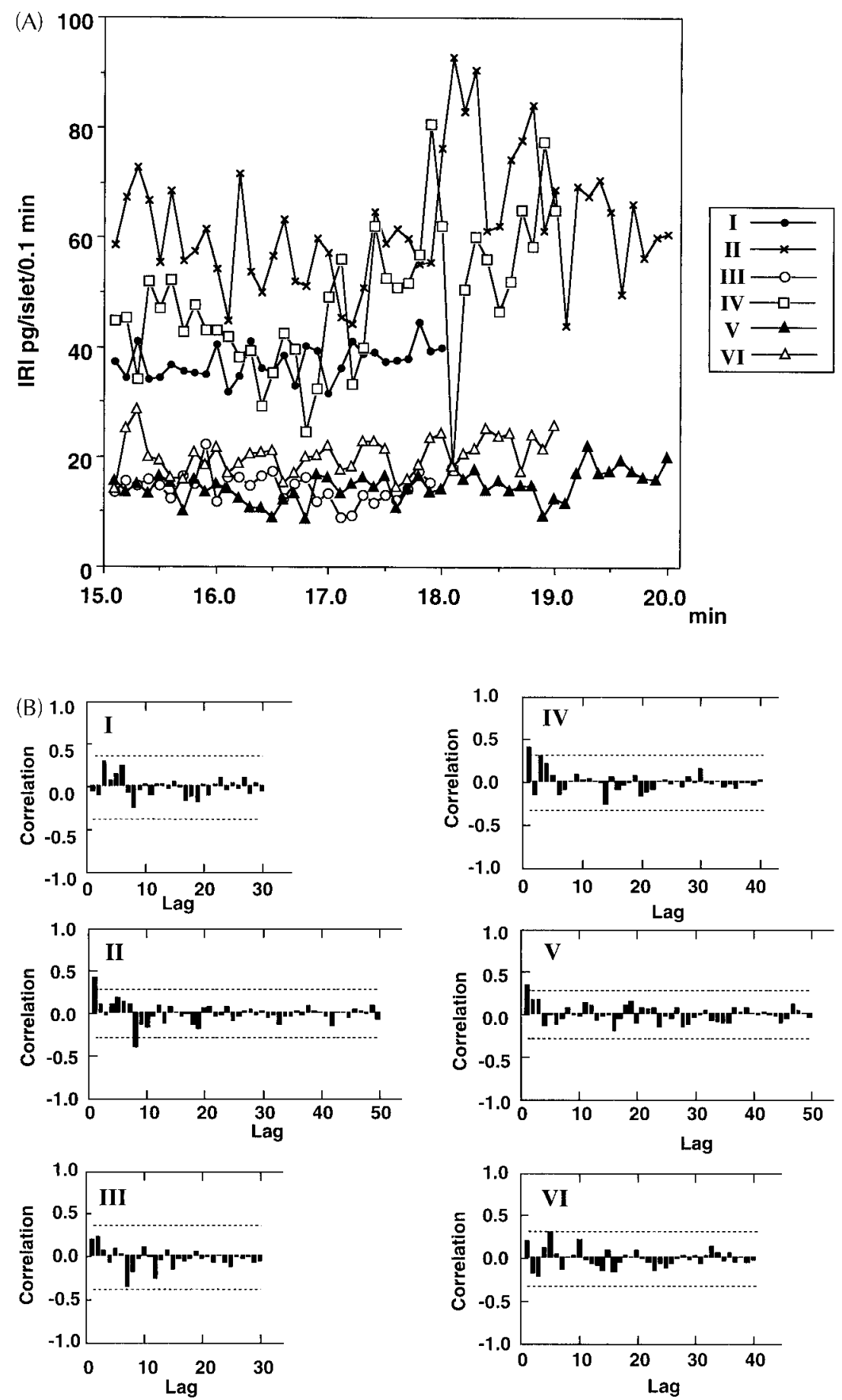

Figure 3 Oscillation of insulin release in the presence of $1.9 \mathrm{mM} \mathrm{Ca}^{2+}$. Representative results from six islets are shown. Actual fluctuation of insulin concentration in the effluent is shown in (A). IRI stands for immunoreactive insulin, and the conversion factor for pg/islet to $\mathrm{nmol} /$ islet is $0 \cdot 1739$. The glucose concentration of the perifusate was raised from 3 to $16.7 \mathrm{mM}$ at time 0 . Fifteen minutes after the initiation of glucose stimulation, perifusate was collected at a 6 -s interval for the duration of 5 min (II and V), 4 min (IV and VI), or 3 min (I and III). Analyses of pulsatility by the partial autocorrelation plot are presented in (B). Each Roman numeral in (A) and (B) corresponds, i.e. the partial autocorrelation plot in (B) I was obtained from the raw data in (A) I, (B) II from (A) II, and so on. The horizontal dotted lines in (B) indicate the level of $P=0 \cdot 05$. Hence, if the height of a bar exceeds the dotted line, a statistically significant pulse exists at that lag (time point). Significant pulses were detected in (B), II, IV, V, and VI, but not in I and III. Upward and downward bars indicate positive and negative deflections respectively. One lag in (B) corresponds to $6 \mathrm{~s}$. 

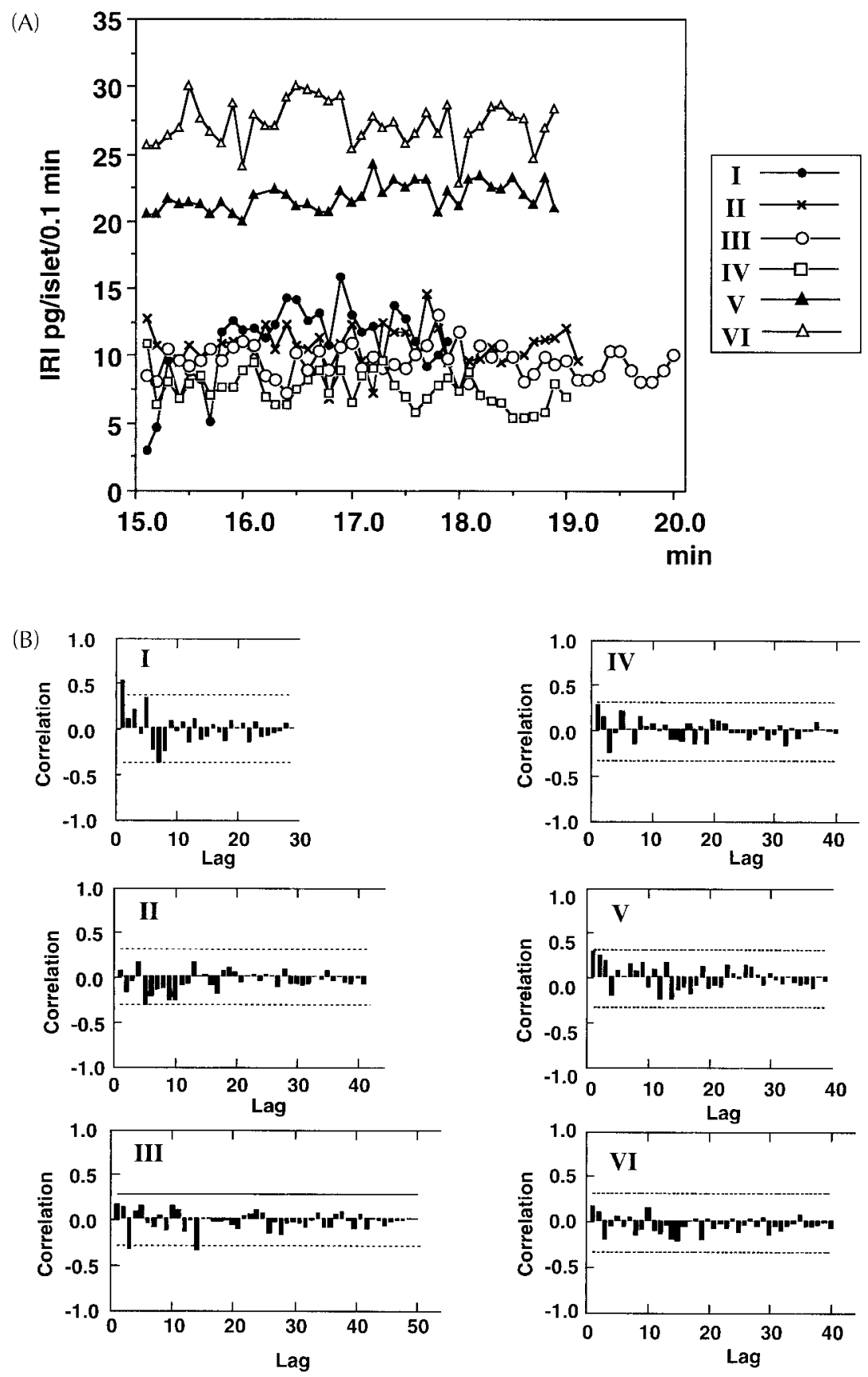

Figure 4 Oscillation of insulin release under the stringent $\mathrm{Ca}^{2+}$-free conditions. The actual fluctuation of insulin concentration in the effluent is shown in (A). IRI stands for immunoreactive insulin, and the conversion factor for pg/islet to nmol/islet is $0 \cdot 1739$. Glucose concentration of perifusate was raised from 3 to $16.7 \mathrm{mM}$ under the stringent $\mathrm{Ca}^{2+}$-free conditions $\left(\mathrm{Ca}^{2+}\right.$ omission with 1 mM EGTA, $6 \mu \mathrm{M}$ forskolin and $100 \mathrm{nM}$ TPA) at time 0 . Fifteen minutes after the initiation of glucose stimulation, the perifusate was collected at a 6-s interval for the duration of $5 \mathrm{~min}$ (III), $4 \mathrm{~min}$ (II, IV, $\mathrm{V}$ and $\mathrm{VI}$ ), or $3 \mathrm{~min}$ (I). Analyses of pulsatility by the partial autocorrelation plot are presented in (B). Each Roman numeral in (A) and (B) corresponds, i.e. the partial autocorrelation plot in (B) I was obtained from the raw data in (A) I, (B) II from (A) II, and so on. Horizontal dotted lines in (B) indicate the level of $P=0 \cdot 05$. Hence, if the height of a bar exceeds the dotted line, a statistically significant pulse exists at that lag (time point). Significant pulses were detected in (B), I, II, and III, but not in IV, V, and VI. Upward and downward bars indicate positive and negative deflections respectively. One lag in (B) corresponds to $6 \mathrm{~s}$. 
stimulating insulin release through ' $\mathrm{K}^{+} \mathrm{ATP}$ channeldependent' and ' $\mathrm{K}+\mathrm{ATP}$ channel-independent and $\mathrm{Ca}^{2+}$ dependent' pathways, whereas, in the latter condition, the hexose is stimulating insulin release selectively through ' $\mathrm{K}^{+} \mathrm{ATP}$ channel-independent and $\mathrm{Ca}^{2+}$-independent' pathway. We used freshly isolated rat islets as material and insulin concentration was determined by using a highly sensitive rat insulin RIA. The most prominent finding in our study is that a high concentration of glucose elicits rapid, oscillatory insulin release even in the stringent $\mathrm{Ca}^{2+}$-free conditions.

Rapid, oscillatory insulin release was found also with $11 \cdot 1 \mathrm{mM}$ glucose in regular KRB buffer (data not shown). Here, islets kept for $4 \mathrm{~h}$ after isolation in regular KRB buffer were employed. The finding strongly suggests that rapid oscillation of insulin release stated above occurs at a physiological concentration of glucose, and that it is not a unique phenomenon to the islets used rapidly after isolation.

Furthermore, we revealed the following intriguing facts. In freshly isolated islets (present data), the amplitude of oscillation was lower and frequency of pulsatility was higher than in cultured mouse islets (Gilon et al. 1993, Gilon \& Henquin 1995, Bergsten et al. 1994, Bergsten 1995, Zaitsev et al. 1995, Westerlund et al. 1996, 1997), indicating that the proportion of functionally coupled $\beta$ cells in the islet is lower in fresh islets. In other words, in cultured islets, a larger fraction of $\beta$ cells/islet appears to be functionally coupled and secreting insulin synchronously, which may be due to a loss of centrally located cells after culture. In the present study, the degree of oscillation was smaller in the absence of $\mathrm{Ca}^{2+}$, although the difference did not reach the statistically significant level. Also, a positive deflection of release with a short duration was predominantly found in the presence of $\mathrm{Ca}^{2+}$. The differences may be mostly, if not entirely, due to elimination of $\mathrm{Ca}^{2+}$ signals under the stringent $\mathrm{Ca}^{2+}$ free conditions.

Pulsatile insulin release by the single pancreatic islets has previously been evaluated mostly using the islets from the ob/ob mouse (Rosario et al. 1986, Bergsten \& Hellman 1993a,b, Bergsten et al. 1994, Bergsten 1995, Zaitsev et al. 1995, Westerlund et al. 1996, 1997) whose islets are hypertrophic and the $\beta$ cell is under intense stimulation because the animal is markedly insulin resistant due to obesity caused by leptin deficiency (Zhang et al. 1994). The islets from normal mice were used in the initial studies (Beigelman et al. 1973a,b, 1976) but more recently only in two studies in which the islets were exposed to $10 \mathrm{mM}$ glucose overnight in culture media and subsequently tested in the presence of a very high concentration of $\mathrm{Ca}^{2+}$, that is $10 \mathrm{mM}$ (Gilon et al. 1993, Gilon \& Henquin 1995). Regarding extracellular $\mathrm{Ca}^{2+}$ concentration $\left(\left[\mathrm{Ca}^{2+}\right] \mathrm{o}\right)$, the previous experiments were carried out in the presence of $10 \mathrm{mM}$ (Rosario et al. 1986, Gilon et al. 1993, Gilon \& Henquin 1995), approximately $2.6 \mathrm{mM}$
(Rosario et al. 1986, Bergsten et al. 1994, Bergsten 1995), or $1.3 \mathrm{mM}$ (Bergsten \& Hellman 1993a,b, Zaitsev et al. 1995, Westerlund et al. 1996, 1997) $\mathrm{Ca}^{2+}$. The majority of studies were carried out using cultured islets (Gilon et al. 1993, Bergsten et al. 1994, Bergsten 1995, Gilon \& Henquin 1995, Zaitsev et al. 1995, Westerlund et al. 1996, 1997) where the central necrosis is unavoidable, especially in larger islets. Nevertheless, from the previous studies, it can be summarized that synchronization of changes in $\left[\mathrm{Ca}^{2+}\right] \mathrm{i}$ and insulin release was evident in the presence of higher $\left[\mathrm{Ca}^{2+}\right]$ o concentrations (Gilon et al. 1993, Bergsten et al. 1994, Bergsten 1995, Gilon \& Henquin 1995) and dissociation of the two was found in the presence of lower $\left[\mathrm{Ca}^{2+}\right]$ o (Zaitsev et al. 1995, Westerlund et al. 1996, 1997), suggesting high $\left[\mathrm{Ca}^{2+}\right] \mathrm{o}$ is a prerequisite for the tight temporal coupling of $\left[\mathrm{Ca}^{2+}\right] \mathrm{i}$ and insulin release to occur. In extrapolation of the data obtained in the presence of lower $\left[\mathrm{Ca}^{2+}\right]$ o (Zaitsev et al. 1995, Westerlund et al. 1996, 1997), our finding that oscillation of insulin release occurs even under stringent $\mathrm{Ca}^{2+}$-free conditions is not totally unexpected.

There are more than several thousand $\beta$ cells in each islet (Pipeleers et al. 1992) so that non-oscillatory insulin release is expected if all $\beta$ cells in the islet secrete insulin, say, randomly or with randomly distributed rhythmicity. Glucose-induced oscillatory elevation of $\left[\mathrm{Ca}^{2+}\right]$ i which propagates from one $\beta$ cell to another may be causing an oscillatory insulin release by the islets as proposed, especially in the presence of high $\left[\mathrm{Ca}^{2+}\right]$ o (Gilon et al. 1993, Bergsten et al. 1994, Bergsten 1995, Gilon \& Henquin 1995). However, oscillatory elevation of $\left[\mathrm{Ca}^{2+}\right] \mathrm{i}$ cannot be a driving force for the oscillation of insulin release under the stringent $\mathrm{Ca}^{2+}$-free conditions because glucose does not cause elevation of $\left[\mathrm{Ca}^{2+}\right] \mathrm{i}$ (Komatsu et al. 1995, 1996). Therefore, under stringent $\mathrm{Ca}^{2+}$-free conditions, functional coupling among $\beta$ cells may be produced by propagation of non-Ca ${ }^{2+}$ ionic events (Atwater et al. 1996), glucose metabolites (Henquin et al. 1998, Tornheim 1997) and/or yet unidentified messengers, which may eventually control the rate of insulin release at the level of exocytosis per se (priming, docking and/or fusion) (Hisatomi et al. 1996, Rorsman 1997, Daniel et al. 1999).

We established oscillatory, coordinated insulin release under stringent $\mathrm{Ca}^{2+}$-free conditions. The data supports the idea that high concentration of glucose generates $\mathrm{Ca}^{2+}$ and non- $\mathrm{Ca}^{2+}$ pulsatile signals at various steps of stimulussecretion coupling, and the hierarchy of them decides the eventual pattern of insulin exocytosis (Henquin et al. 1998). Further studies are needed to elucidate the entire picture of mediation of oscillatory insulin release.

\section{Acknowledgements}

This study was supported by a Grant-in-Aid for Scientific Research from the Ministry of Education, Japan (to T A). 


\section{References}

Aizawa T, Sato Y, Komatsu M \& Hashizume K 1992 ATP-sensitive $\mathrm{K}^{+}$channel-independent, insulinotropic action of glucose in the B-cell. Endocrine Regulation 26 159-162.

Aizawa T, Sato Y, Ishihara F, Komatsu M, Taguchi N, Hashizume K \& Yamada T 1994 ATP-sensitive $\mathrm{K}^{+}$channel-independent glucose action in rat pancreatic $\beta$-cell. American Journal of Physiology 266 C622-C627.

Aizawa T, Asanuma N, Terauchi Y, Suzuki N, Komatsu M, ItohN, Nakabayashi T, Hidaka H, Ohnota H, Yamauchi K, Yasuda K, Yazaki Y, Kadowaki T \& Hashizume K 1996 Analysis of the pancreatic $\beta$ cell in the mouse with targeted disruption of the pancreatic $\beta$ cell-specific glucokinase gene. Biochemical and Biophysical Research Communications 229 460-465.

Aizawa T, Komatsu M, Asanuma N, Sato Y \& Sharp GWG 1998 Glucose action 'beyond ionic events' in the pancreatic $\beta$ cell. Trends in Pharmacological Sciences 19 496-499.

Asanuma N, Aizawa T, Sato Y, Schermerhorn T, Komatsu M, Sharp GWG \& Hashizume K 1997 Two signaling pathways from the upper glycolytic flux and from the mitochondria converge to potentiate insulin release. Endocrinology 138 751-755.

Atwater I, Mears D \& Rojas E 1996 Electrophysiology of the pancreatic $\beta$-cell. In Diabetes Mellitus. A Fundamental and Clinical Text, pp 78-102. Eds D LeRoith, SI Taylor \& JM Olefsky. Philadelphia: Lippincott-Raven.

Beigelman PM, Shu MJ \& Thomas LJ Jr 1973a Insulin from individual isolated mouse islets of Langerhans. Biochemical Medicine 7 91-96.

Beigelman PM, Thomas LJ, Slavin BG, Shu MJ \& Bessman SP $1973 b$ Insulin from individual isolated islets of Langerhans. 1. Response to glucose. Biochemical Medicine 8 392-402.

Beigelman PM, Thomas LJ, Shu MJ \& Bessman SP 1976 Insulin from individual isolated islets of Langerhans 2. Effect of glucose in varying concentrations. Journal of Physiology 72 721-728.

Bergsten P 1995 Slow and fast oscillations of cytoplasmic $\mathrm{Ca}^{2+}$ in pancreatic islets correspond to pulsatile insulin release. American Journal of Physiology 268 E282-E287.

Bergsten P \& Hellman B 1993a Glucose-induced amplitude of regulation of insulin secretion from individual pancreatic islets. Diabetes 42 670-674.

Bergsten P \& Hellman B 1993 b Glucose-induced cycles of insulin release can be resolved into distinct periods of secretory activity. Biochemical and Biophysical Research Communications 192 1182-1188.

Bergsten P, Grapengiesser E, Gylfe E, Tengholm A \& Hellman B 1994 Synchronous oscillations of cytoplasmic $\mathrm{Ca}^{2+}$ and insulin release in glucose-stimulated pancreatic islets. Journal of Biological Chemistry 269 8749-8753.

Daniel S, Noda M, Straub SG \& Sharp GW 1999 Identification of the docked granule pool responsible for the first phase of glucosestimulated insulin secretion. Diabetes 48 1686-1690.

Gembal M, Gilon P \& Henquin JC 1992 Evidence that glucose can control insulin release independently from its action on ATPsensitive $\mathrm{K}^{+}$channels in mouse B cells. Journal of Clinical Investigation 89 1288-1295.

Gilon P \& Henquin J-C 1995 Distinct effects of glucose on the synchronous oscillations of insulin release and cytoplasmic $\mathrm{Ca}^{2+}$ concentration measured simultaneously in single mouse islets. Endocrinology $1365725-5730$.

Gilon P, Shepherd RM \& Henquin J-C 1993 Oscillation of secretion driven by oscillation of cytoplasmic $\mathrm{Ca}^{2+}$ as evidenced in single pancreatic islets. Journal of Biological Chemistry 268 22265-22268.

Henquin J-C, Jonas JC \& Gilon P 1998 Functional significance of $\mathrm{Ca}^{2+}$ oscillations in pancreatic $\beta$ cells. Diabetes and Metabolism 24 $30-36$.
Hisatomi M, Hidaka H \& Niki I $1996 \mathrm{Ca}^{2+} /$ calmodulin and cyclic 3,5 ' adenosine monophosphate control movement of secretory granules through protein phosphorylation/dephosphorylation in the pancreatic $\beta$-cell. Endocrinology 137 4644-4649.

Komatsu M, Schermerhorn T, Aizawa T \& Sharp GWG 1995 Glucose stimulation of insulin release in the absence of extracellular $\mathrm{Ca}^{2+}$ and in the absence of any rise in intracellular $\mathrm{Ca}^{2+}$ in rat pancreatic islets. PNAS 92 10728-10732.

Komatsu M, Schermerhorn T, Straub S \& Sharp GWG 1996 Pituitary adenylate cyclase-activating peptide, carbacol, and glucose stimulate insulin release in the absence of an increase in intracellular $\mathrm{Ca}^{2+}$. Molecular Pharmacology 50 1047-1054.

Komatsu M, Schermerhorn T, Noda M, Straub SG, Aizawa T \& Sharp GWG 1997 Augmentation of insulin release by glucose in the absence of extracellular $\mathrm{Ca}^{2+}$ : new insights into stimulussecretion coupling. Diabetes 46 1928-1938.

Komatsu M, Yajima H, Yamada S, Kaneko T, Sato Y, Yamauchi K, Hashizume K \& Aizawa T 1999 Augmentation of $\mathrm{Ca}^{2+}$-stimulated insulin release by glucose and long chain fatty acids in rat pancreatic islets: free fatty acids mimic ATP-sensitive $\mathrm{K}^{+}$channel-independent insulinotropic action of glucose. Diabetes 48 1543-1549.

Pipeleers D, Kiekens R \& In'tveld P 1992 Morphology of the pancreatic $\beta$-cell. In Insulin: Molecular Biology to Pathology, pp 5-31. Eds FM Ashcroft \& SJH Ashcroft. Oxford: IRL Press.

Rorsman P 1997 The pancreatic $\beta$-cell as a fuel sensor: an electrophysiologist's viewpoint. Diabetologia 40 487-495.

Rosario LM, Atwater I \& Scott AM 1986 Pulsatile insulin release and electrical activity from single ob/ob mouse islets of Langerhans. Advances in Experimental Medicine and Biology 211 413-425.

Sato Y, Aizawa T, Komatsu M, Okada N \& Yamada T 1992 Dual functional role of membrane depolarization $/ \mathrm{Ca}^{2+}$ influx in rat pancreatic B-cell. Diabetes 41 438-443.

Sato Y, Nenquin M \& Henquin JC 1998 Relative contribution of $\mathrm{Ca}^{2+}$-dependent and $\mathrm{Ca}^{2+}$-independent mechanisms to the regulation of insulin secretion by glucose. FEBS Letters $\mathbf{4 2 1}$ $115-119$.

Taguchi N, Aizawa T, Sato Y, Ishihara F \& Hashizume K 1995 Mechanism of glucose-induced biphasic insulin release by pancreatic B-cell: physiological role of ATP-sensitive $\mathrm{K}^{+}$ channel-independent glucose action. Endocrinology 136 3942-3948.

Tornheim K 1997 Are metabolic oscillations responsible for normal oscillatory insulin secretion? Diabetes $461375-1380$.

Westerlund J, Hellman B \& Bergsten P 1996 Pulsatile insulin release from mouse islets occurs in the absence of stimulated entry of $\mathrm{Ca}^{2+}$. Journal of Clinical Investigation 97 1860-1863.

Westerlund J, Gylfe E \& Bergsten P 1997 Pulsatile insulin release from pancreatic islets with nonoscillatory elevation of cytoplasmic $\mathrm{Ca}^{2+}$. Journal of Clinical Investigation 100 2547-2551.

Yajima N, Komatsu M, Schermerhorn T, Aizawa T, Kaneko T, Nagai M, Sharp GWG \& Hashizume K 1999 Cyclic AMP enhances insulin secretion by an action on the ATP-sensitive $\mathrm{K}^{+}$ channel-independent pathway of glucose signaling in rat pancreatic islets. Diabetes 48 1006-1012.

Zaitsev S, Efendic S, Arkhammar P, Bertorello AM \& Bergren P-O 1995 Dissociation between changes in cytoplasmic free concentration and insulin secretion as evidenced from measurements in mouse single pancreatic islets. PNAS 92 9712-9716.

Zhang Y, Proenca R, Maffei M, Barone M, Leopold L \& Friedman JM 1994 Positional cloning of the mouse obese gene and its human homologue. Nature 372 425-432.

Received 29 December 1999

Accepted 4 May 2000 